\title{
MyABFM Portfolio: Improving Communication on Certification Activities and Progress, Designed by Family Physicians, for Family Physicians
}

\author{
Erin Mybre, MBA, Kevin Graves, MBA, Shannon White, BS, Elizabeth Baxley, MD, \\ Kevin Rode, BS, PMP, and Warren P. Newton, MD, MPH
}

(J Am Board Fam Med 2021;34:673-674.)

Participation in continuous certification involves ongoing, periodic engagement with a series of activities intended to help family physicians regularly assess their own knowledge strengths and gaps, use resources to help close those gaps and continue learning, and improve care delivery and outcomes. The American Board of Family Medicine (ABFM) has sought to continually improve the quality, relevance, and process of certification, largely informed by Diplomate feedback. However, even desired changes create the need for broad and effective communication to enable participating family physicians to keep up so that they have contemporary understanding of what is available and required to gain, and maintain, certification.

The challenge of communicating in a way that reaches 98,000 busy family physicians in varied practice types and locations is daunting, especially when they are besieged with information from many different professional sources. Let us face it, participation in certification activities is a "just in time" phenomenon—even when a Diplomate has opened an e-mail or newsletter and read its contents, if it does not apply to him or her right away, it may not be recalled when the information is needed later.

Enter MyABFM Portfolio (https://portfolio. theabfm.org/)—a substantially redesigned physician portfolio that recently launched to all currently certified Diplomates, with a goal of providing a clean, purpose-driven, and personalized experience for users. Residents will see a new personalized portfolio design in late summer.

Conflict of interest: The authors are employees of the American Board of Family Medicine.

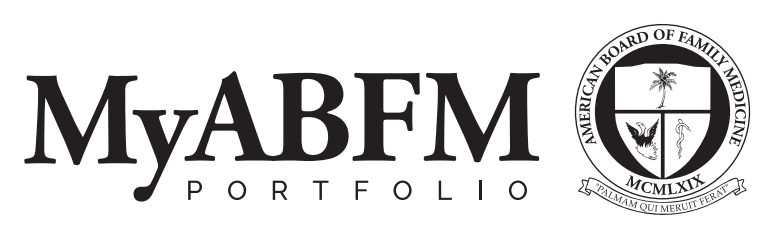

The guiding principles for this effort, which began in June 2019, were to provide all information that Diplomates may need, at their fingertips, with minimal clicks; to ensure that it is highly personalized and easy to understand; to reduce their need to provide us with information that we already have; to clearly display their current status, future needs, and timelines; and to provide them with easy access to the answers to the most common questions we have heard from physicians over time. A final guiding principle is to continuously improve and maintain the MyABFM Portfolio with ongoing enhancements.

A key feature of this nearly 2-year effort was use of a user-centered design approach. Diplomate input has guided MyABFM Portfolio's design from the very beginning and at each stage of development, with more than 180 physician contributors providing critical feedback into the process. In-person focus groups allowed for more than 100 Diplomates to influence the design of various iterations of the dashboard-the main point of entry into the portfolio and where the most highly relevant information is presented. In-person focus groups were held at the 2019 Family Medicine Experience conference and the Florida Academy of Family Physicians (FAFP) chapter annual meeting that year. These sessions aided staff in determining specific features Diplomates wanted and how those features should be presented. Then, for each component and for each intended audience, we sought feedback virtually with small groups and individual interviews. Finally, since June 2020, we 
implemented a "soft launch" with almost 50 volunteers interacting with the site and continuously providing feedback. Six resident physicians were recruited to provide a "residents' view." In addition, we partnered with the Ohio AFP chapter to codesign a certification planner that will be deployed to allow for proactive planning of your 3-year certification stage activities. This planner will help to distribute the continuous certification process more evenly and avoid the "December effect" that plagues many physicians near the end of a 3-year stage. This will be available later this year.

The new features incorporated in MyABFM Portfolio are important. First, we have seen an increasing number of physicians use their phones and other mobile platforms to do their daily work. At each stage of the process, improvements in mobile responsiveness were incorporated. Second, experience with our website redesign in March 2019 convinced us that having less text improved readability and understanding, so we have systematically reduced the text on each page of the MyABFM Portfolio and added informative graphics that illustrate a Diplomate's current status. No more "buckets" to fill. A dynamic, circular pie graph that will fill in as activities are added and completed and will clearly demonstrate the remaining activities needed to complete. Direct links are also provided to easily access and complete open requirements. Some Diplomates reported getting easily lost within the current portfolio. So, in addition to simplifying the navigation, we have added an easy-to-use search function.

Finally, some wanted easier access to locate answers on your own, without having to call or email, especially after hours. While our support center staff is available and eager to assist physicians throughout the week, including Saturday and Sunday, the new MyABFM Portfolio provides the opportunity for Diplomates to find answers to their most frequently asked questions in our new common support requests section without having to wait for a response. In addition, they can initiate a chat with our support center during regular hours for an instant response, or open a support request to our team online and receive an answer to the latter via email and within your portfolio account.

Of course, the new MyABFM Portfolio retains many of the strengths of the old portfolio: automatic transfer of continuing medical education (CME) credit from the American Academy of Family Physicians, which will now come across incrementally as it is logged; easy access to, and CME credit for, knowledge self-assessment and performance improvement activities; the PI locator to assist Diplomates in curating the most relevant performance improvement activities based on practice type and personal interests; and automated updating of Diplomates medical license(s) that only require Diplomates to verify, enabling reduced burden of data entry. In addition, users can continue to learn about ABFM's research and policy work.

A fundamental redesign focused on improved and personalized experience for its end users, required the energy, passion, and commitment of a large number of people with different talents and perspectives-in this case, the many talented staff from different departments within ABFM working nearly 2 years to get ready for release. Yet, as the curtain goes up on the new portfolio, our work is not done. Our commitment to continuous improvement will equally apply to learning how MyABFM Portfolio is working for you. Log in, click around, and let us know what you think by going to the upper right corner and select "give feedback" in the dropdown menu. We want to know what works and what does not so that we can dynamically evolve your portfolio to meet your needs, over time!

To see this article online, please go to: http://jabfm.org/content/ 34/3/673.full. 